\title{
Clinicians' Implicit Ethnic/Racial Bias and Perceptions of Care Among Black and Latino Patients
}

Irene V. Blair, $P b D^{1}$

Jobn F. Steiner, $M D, M P H^{2}$

Diane L. Fairclough, DrPH

Rebecca Hanratty, MD

David W. Price, $M D^{2}$

Holen K. Hirsh, $P b D^{1}$

Leslie A. Wright, $\mathrm{MA}^{2}$

Michael Bronsert, $P b D^{3}$

Elbum Karimkbani, $M P H^{5}$

David J. Magid, MD

Edward P. Havranek, $M D^{5}$

'Department of Psychology and Neuroscience, University of Colorado Boulder, Boulder, Colorado

${ }^{2}$ Institute for Health Research, Kaiser Permanente Colorado, Denver, Colorado

${ }^{3}$ Colorado Health Outcomes Center, University of Colorado Denver, Denver, Colorado

${ }^{4}$ Division of Internal Medicine, Denver Health, Denver, Colorado

${ }^{5}$ Division of Cardiology, Denver Health, Denver, Colorado

Conflicts of interest: authors report none.

\section{CORRESPONDING AUTHOR}

Irene $\mathrm{V}$. Blair, $\mathrm{PhD}$

University of Colorado Boulder

Department of Psychology and

Neuroscience

Boulder, CO 80309-0345

Irene.Blair@Colorado.edu

\begin{abstract}
PURPOSE We investigated whether clinicians' explicit and implicit ethnic/racial bias is related to black and Latino patients' perceptions of their care in established clinical relationships.

METHODS We administered a telephone survey to 2,908 patients, stratified by ethnicity/race, and randomly selected from the patient panels of 134 clinicians who had previously completed tests of explicit and implicit ethnic/racial bias. Patients completed the Primary Care Assessment Survey, which addressed their clinicians' interpersonal treatment, communication, trust, and contextual knowledge. We created a composite measure of patient-centered care from the 4 subscales.
\end{abstract}

RESULTS Levels of explicit bias were low among clinicians and unrelated to patients' perceptions. Levels of implicit bias varied among clinicians, and those with greater implicit bias were rated lower in patient-centered care by their black patients as compared with a reference group of white patients $(P=.04)$. Latino patients gave the clinicians lower ratings than did other groups $(P<.0001)$, and this did not depend on the clinicians' implicit bias $(P=.98)$.

CONCLUSIONS This is among the first studies to investigate clinicians' implicit bias and communication processes in ongoing clinical relationships. Our findings suggest that clinicians' implicit bias may jeopardize their clinical relationships with black patients, which could have negative effects on other care processes. As such, this finding supports the Institute of Medicine's suggestion that clinician bias may contribute to health disparities. Latinos' overall greater concerns about their clinicians appear to be based on aspects of care other than clinician bias.

Ann Fam Med 2013;11:43-52. doi:10.1370/afm.1442

\section{INTRODUCTION}

$\mathrm{P}$ rimary care clinicians serve as the cornerstone of the health care system and are required to possess many skills. Patient-centeredness is 1 of 6 key dimensions of high-quality health care, ${ }^{1}$ and if clinicians are to provide such care, they must be able to engage patients in a collaborative partnership.

The importance of the clinician-patient relationship is underscored by demonstrated links between the quality of the relationship and a number of processes and outcomes of care, including patients' adherence to medical advice, ${ }^{2-6}$ decision to remain with a clinician, ${ }^{7}$ satisfaction with care, ${ }^{3}$ and clinical outcomes of care. ${ }^{3,8,9}$

Ethnic/racial minorities appear to be at a disadvantage in this aspect of health care. ${ }^{10-17}$ In addition to cultural and language barriers, there have been long-standing concerns that clinician bias may contribute to lowerquality clinical relationships. ${ }^{18,19}$

A 2003 report ${ }^{18}$ by the Institute of Medicine noted, "It is likely that the vast majority [of clinicians] endorse egalitarian and non-racist attitudes." 
But also, "[there is] strong but circumstantial evidence for the role of bias, stereotyping, prejudice, and clinical uncertainty" in the genesis of health disparities. The observation that clinicians are unlikely to directly express ethnic/racial bias yet may still deliver care that is influenced by unrecognized bias is consistent with research in social psychology that demonstrates that bias exists on explicit and implicit levels. Whereas explicit bias is overt and freely expressed, implicit bias may not be consciously acknowledged and operates in more subtle ways. ${ }^{20-22}$ For example, a clinician with implicit bias may unconsciously exhibit negative behavior or poor communication with a black patient, as has been shown in laboratory research. ${ }^{21,23-25}$ In addition to reducing the patient's comfort and trust, such actions may impede the flow of information, lead to shorter interviews, and reduce the patient's understanding of and resolve to follow medical advice. ${ }^{2-6,13}$ Few studies have directly investigated whether clinician bias is related to communication, interpersonal treatment, and trust in ongoing clinical relationships.

In a prior study, ${ }^{26}$ we found that two-thirds of participating primary care clinicians showed some implicit ethnic/racial bias that favored whites, even as they rejected explicit expressions of bias. In the current study, we contacted a large sample of patients of those clinicians and asked them to rate the degree to which their clinicians were patient-centered during their interactions. We then examined those ratings as a function of the patients' ethnicity/race and the clinicians' implicit and explicit ethnic/racial bias. We hypothesized that clinicians with higher levels of implicit bias would be rated less favorably by their minority patients than clinicians with lower levels of implicit bias.

\section{METHODS}

Study Population and Data Collection: Clinicians We derived data about the implicit bias of clinicians from a prior study ${ }^{26}$ in which adult primary care clinicians from 3 health care organizations were invited to complete measures of their implicit and explicit ethnic/ racial attitudes $(\mathrm{N}=210,60 \%$ participation rate). Data from that study were included in the present study for 2 organizations: Denver Health and Kaiser Permanente Colorado. Denver Health is an integrated safety-net health care system and is nationally recognized for its model of care to underserved, indigent, and minority patients. ${ }^{27,28}$ Denver Health community clinics see more than 100,000 unique patients each year $(15 \%$ black, $60 \%$ Latino, 16\% white, and $9 \%$ other). Kaiser Permanente Colorado is a closed-panel, group-model, not-for-profit health maintenance organization with approximately 480,000 members in the Denver area
(5\% black, $17 \%$ Latino, $74 \%$ white, and $4 \%$ other). The institutional review board for each institution approved the study design and procedures.

\section{Implicit Bias}

We measured implicit bias against blacks and against Latinos with 2 Implicit Association Tests (IATs). ${ }^{29}$

The IAT measures implicit bias ${ }^{29-32}$ by the speed with which a person can respond to a group and positive vs negative words. Implicit bias is shown, for example, if the person is significantly faster when black faces and negative words require the same response while white faces and good words require another response, compared with the reverse pairing. The larger this performance difference, the stronger the implicit bias for that person (demonstration is available at https://implicit. harvard.edu). The IAT has been widely used, and its psychometric properties and methodologic strengths and limitations have been extensively reviewed..$^{30-34}$ The 2 IATs completed by the clinicians in this study were validated in previous research to measure implicit bias against blacks compared with whites and against Latinos compared with whites. ${ }^{26,35}$ Possible scores ranged from -2 to +2 , with negative scores indicating bias against whites, positive scores indicating bias against blacks or Latinos, and 0 indicating no bias.

\section{Explicit Bias}

The clinicians were asked to indicate their explicit attitudes toward blacks, Latinos, and whites on 2 standard measures ${ }^{36,37}$ : Feeling Thermometers (with possible scores of 0 to 100 for "cool" to "warm" feelings) and a set of semantic differential scales (7-point trait ratings of "hard-working to lazy," "wise to foolish," and "cooperative to hostile").

\section{Study Population and Data Collection: Patients}

We obtained primary data from patients in a broader study on hypertension care; thus, all patients had diagnosed hypertension. Patients were included in the sampling frame for this study if they received regular care from a participating clinician and their ethnicity/race of record was black, Latino, or white. The patients were stratified by clinician and ethnicity/race, and then randomly selected within each stratum up to a maximum of 12 patients. This initial screening produced 7,437 patients, of whom 1,308 were subsequently determined to be ineligible for the study $(1,055$ had incorrect contact information, 210 did not confirm their primary care clinician, and 43 self-identified their ethnicity/race as other than any of the 3 groups included in this study).

A professional survey company attempted to call the 6,129 eligible patients by telephone and adminis- 
ter the questionnaire in either English or Spanish. If telephone contact could not be made, a written questionnaire in both English and Spanish was sent to the patient's last known address. All participants were sent a $\$ 10$ gift card.

\section{Patient Survey}

Four subscales were administered from the wellvalidated Primary Care Assessment Survey ${ }^{38}$ (PCAS): interpersonal treatment, communication, trust, and contextual knowledge. Example items include rating the clinician on "caring and concern for you" (interpersonal treatment), "you leave your doctor's office with unanswered questions" (communication), "my doctor sometimes pretends to know things when really not sure" (trust), and "knowledge about you as a person (your values and beliefs)" (contextual knowledge). Each subscale is scored from 0 to 100, with higher scores indicating a higher level of the attribute; the 4 subscales were averaged to create a composite measure of patient-centeredness. Additional survey questions assessed patients' sociodemographic characteristics. The survey was conducted from mid-2010 to early 2011.

\section{Identification of Patients' Primary Care Clinician} A clinician was identified for a patient only if the patient (1) saw that clinician for a majority of primary care visits in 3 years, (2) visited that clinician at least 3 times in that period, and (3) confirmed on the questionnaire that he/she received regular care from that clinician. The patient was also asked how many years he/she had been going to that clinician.

\section{Ethnicity/Race}

Patients were first screened by the ethnicity/race recorded in their medical files to include only black, Latino, or white patients. Those who were subsequently contacted were asked to identify their ethnicity/race (with results showing $90 \%$ agreement with records), and their self-identified ethnicity/race was used for analysis.

\section{Statistical Analyses}

We evaluated differences in patients' demographics using the Pearson $\chi^{2}$ test for categorical variables, the nonparametric Kruskal-Wallis test for ordered categorical variables, and analysis of variance for continuous variables. The primary dependent variables were the patients' responses to the 4 PCAS subscales and the composite measure of patient-centeredness, with the patients' ethnicity/race and each measure of their clinicians' ethnic/racial bias used as predictors. The specific effect of interest was the degree to which black or Latino patients differed from white patients in their ratings of the clinicians, and critically, the extent to which those differences were themselves predicted by the clinicians' ethnic/racial bias (analyzed as continuous variables). Measures of clinician bias against blacks were used in predicting black patients' ratings; $s_{i}$ measures of clinician bias against Latinos were used in predicting Latino patients' ratings. Because patients were nested under clinicians, who were themselves nested under clinics, the data were analyzed using hierarchical linear modeling or mixed effects models. White patients were always used as the reference group. We also considered a nonlinear relationship between patient's survey ratings and clinician bias using a simple linear spline with 5 knots.

Supplementary analyses were conducted to examine additional patient background characteristics (sex, age, socioeconomic status, and, for Latinos only, Spanish and English language proficiency) as statistical controls and to assess subgroup differences. Age was analyzed in decades, and socioeconomic status was analyzed as a dichotomous variable in terms of education (high school or less vs at least some college). Reported income was not used for socioeconomic status because of missing data. Spanish and English language proficiency was analyzed as a dichotomous variable: patients were coded as having greater Spanish than English proficiency if they chose to complete the survey in Spanish or they reported that they were fluent in Spanish but less than fluent in English; all other patients were assigned to the alternate category.

\section{RESULTS}

From the original group of 210 clinicians who had completed the measures of ethnic/racial bias, ${ }^{26} 134$ (64\%) met this study's inclusion criteria. These clinicians' characteristics- $54 \%$ female, $75 \%$ white, and $50 \%$ with more than 10 years of clinical experiencewere nearly identical to those previously reported for the full clinician sample. ${ }^{26}$ As in the full sample, approximately two-thirds of the clinicians had implicit bias against blacks ( $43 \%$ moderate to strong) and Latinos (51\% moderate to strong), while reporting very little explicit bias against either group.

Of the 6,129 patients in the recruitment pool, 2,908 $(47 \%)$ completed the survey questionnaire. Reasons for nonparticipation varied: 1,878 were unreachable, 558 were unable (eg, because they had died or had longterm disability), 780 declined, and 5 did not answer enough questions. Characteristics of the participating and nonparticipating patients are shown in Table 1.

Among participating patients, all 3 ethnic/racial groups had well-established relationships with their clinicians: two-thirds of each group saw their named 


\section{Table 1. Characteristics of Participating and Nonparticipating Patients}

\begin{tabular}{|c|c|c|c|c|c|}
\hline \multirow[b]{2}{*}{ Characteristic } & \multicolumn{2}{|c|}{ Recruitment Sample } & \multicolumn{3}{|c|}{$\begin{array}{l}\text { Final Patient Sample } \\
\text { by Ethnicity/Race }(\mathbf{N}=2,908)\end{array}$} \\
\hline & $\begin{array}{l}\text { Nonparticipants } \\
(\mathrm{n}=3,221)\end{array}$ & $\begin{array}{l}\text { Participants } \\
(\mathrm{n}=2,908)\end{array}$ & $\begin{array}{c}\text { Black } \\
(n=612)\end{array}$ & $\begin{array}{c}\text { Latino } \\
(n=859)\end{array}$ & $\begin{array}{c}\text { White } \\
(n=1,437)\end{array}$ \\
\hline Female, No. (\%) $)^{a, b}$ & $1,690(52)$ & $1,694(58)$ & $369(60)$ & $539(63)$ & $786(55)$ \\
\hline \multicolumn{6}{|l|}{ Age, No. (\%), } \\
\hline $18-35 y$ & $108(3)$ & $67(2)$ & $25(4)$ & $29(3)$ & $13(1)$ \\
\hline $36-55$ y & $1,115(36)$ & $973(33)$ & $234(38)$ & $314(37)$ & $425(30)$ \\
\hline$\geq 56$ y & $1,958(61)$ & $1,868(64)$ & $353(58)$ & $516(60)$ & $999(70)$ \\
\hline \multicolumn{6}{|l|}{ Ethnicity/race, No. (\%) } \\
\hline Black & $560(17)$ & $612(21)$ & - & - & - \\
\hline Latino & $1,146(36)$ & $859(30)$ & - & - & - \\
\hline White & $1,515(47)$ & $1,437(49)$ & - & - & - \\
\hline \multicolumn{6}{|l|}{ Education, No. (\%) ${ }^{\mathrm{b}}$} \\
\hline High school not completed & - & $529(18)$ & $91(15)$ & $355(42)$ & $83(5)$ \\
\hline High school diploma or GED & - & $773(27)$ & $185(30)$ & $237(28)$ & $351(24)$ \\
\hline $1-3$ y college & - & $866(30)$ & $215(35)$ & $167(19)$ & $484(34)$ \\
\hline$\geq 4$ y college & - & $714(24)$ & $118(20)$ & $88(11)$ & $508(35)$ \\
\hline Unknown & - & $26(1)$ & $3(<1)$ & $12(1)$ & $11(1)$ \\
\hline \multicolumn{6}{|l|}{ Household income, No. $(\%)^{b}$} \\
\hline$\leq \$ 15,000$ & - & $1,026(35)$ & $274(45)$ & $396(46)$ & $356(25)$ \\
\hline$\$ 16,000-\$ 35,000$ & - & $555(19)$ & $133(22)$ & $184(21)$ & $238(17)$ \\
\hline$\$ 36,000-\$ 55,000$ & - & $408(14)$ & $68(11)$ & $88(10)$ & $252(18)$ \\
\hline$\geq \$ 56,000$ & - & $717(25)$ & $100(16)$ & $124(14)$ & $493(34)$ \\
\hline Unknown & - & $202(7)$ & $37(6)$ & $67(8)$ & $98(7)$ \\
\hline \multicolumn{6}{|l|}{ Language proficiency, ${ }^{c}$ No. $(\%)^{b}$} \\
\hline Spanish > English & - & $268(9)$ & $5(1)$ & $260(30)$ & $3(<1)$ \\
\hline Alternate category & - & $2,640(91)$ & 607 (99) & $599(70)$ & $1,434(>99)$ \\
\hline \multicolumn{6}{|l|}{$\begin{array}{l}\text { Proportion of primary care } \\
\text { visits with clinician, No. }(\%)^{b}\end{array}$} \\
\hline $.50-.59$ & $520(16)$ & $446(15)$ & $85(14)$ & $137(16)$ & $224(16)$ \\
\hline $.60-.69$ & $530(16)$ & $471(16)$ & $84(14)$ & $133(15)$ & $254(18)$ \\
\hline $.70-.79$ & $552(17)$ & $519(18)$ & $99(16)$ & $161(19)$ & $259(18)$ \\
\hline $.80-.89$ & $644(20)$ & $594(20)$ & $144(24)$ & $182(21)$ & 268 (19) \\
\hline $.90-1.0$ & $975(30)$ & $878(30)$ & $200(33)$ & $246(29)$ & $432(30)$ \\
\hline $\begin{array}{l}\text { Visits with clinician in } 3 y \text {, } \\
\text { mean No. (SD) }\end{array}$ & $\begin{array}{c}7.38 \\
(5.35)\end{array}$ & $\begin{array}{c}7.81 \\
(5.70)\end{array}$ & $\begin{array}{l}8.16 \\
(6.05)\end{array}$ & $\begin{array}{c}8.51 \\
(5.91)\end{array}$ & $\begin{array}{l}7.23 \\
(5.36)\end{array}$ \\
\hline $\begin{array}{l}\text { Years with clinician, } \\
\text { mean No. (SD) }\end{array}$ & - & $\begin{array}{c}3.40 \\
(1.07)\end{array}$ & $\begin{array}{l}3.35 \\
(1.09)\end{array}$ & $\begin{array}{c}3.37 \\
(1.16)\end{array}$ & $\begin{array}{c}3.45 \\
(1.00)\end{array}$ \\
\hline \multicolumn{6}{|l|}{ GED = general equivalency degree . } \\
\hline $\begin{array}{l}\text { a Participants and nonparticipants di } \\
\text { b Ethnic/racial groups differ, } P<.05 . \\
\text { ' Greater proficiency in Spanish than } \\
\text { questionnaire that they were fluent } \mathrm{i}\end{array}$ & assigned if (1) pat & pleted the ques & instead of & or (2) patie & orted on the \\
\hline
\end{tabular}

clinician for at least $70 \%$ of their primary care visits, the average clinical relationship had been ongoing for more than 3 years, and there had been an average of more than 7 visits with the clinician in 3 years.

\section{Primary Outcomes}

Patients' Ratings of Clinicians' Patient-Centeredness Patients in all 3 groups evaluated their clinicians favorably on the measures of patient-centered care (Table 2 ), similar to what has been found in previous largescale studies., ${ }^{3,78-42}$ Compared with white patients, black patients gave mostly equivalent ratings to the clinicians (composite scale difference, $P=.84$ ), whereas Latino patients gave comparatively lower ratings (composite scale difference, $P<.0001)$.

\section{Patients' Ratings as a Function of Clinicians' Implicit Bias}

There were consistent associations between clinicians' implicit bias and their black patients' evaluations of them: the stronger the clinicians' implicit preference for whites over blacks, the lower their black patients rated 


\section{Table 2. PCAS Scores by Patients' Ethnicity/Race}

\begin{tabular}{|c|c|c|c|}
\hline \multirow[b]{2}{*}{ Scale $(\alpha)$ and Description } & \multicolumn{3}{|c|}{ Score, Mean (SD) } \\
\hline & Black & Latino & White \\
\hline \multicolumn{4}{|l|}{ Subscale ${ }^{a}$} \\
\hline $\begin{array}{l}\text { Interpersonal treatment }(\alpha=.94) ; 5 \text { items on the } \\
\text { clinician's patience, friendliness, caring, respect, } \\
\text { and time spent with the patient }\end{array}$ & $84(19)$ & $81^{\mathrm{b}}(19)$ & $86(18)$ \\
\hline $\begin{array}{l}\text { Communication ( } \alpha=.93) ; 6 \text { items on the thorough- } \\
\text { ness of the clinician's questions, attention to the } \\
\text { patient, clarity of explanations and instructions, } \\
\text { and help in making decisions about care }\end{array}$ & $84(18)$ & $80^{b}(19)$ & $84(17)$ \\
\hline $\begin{array}{l}\text { Trust }(\alpha=.85) ; 8 \text { items on the clinician's integrity } \\
\text { and role as the patient's agent in the system }\end{array}$ & $79^{b}(16)$ & $76^{b}(15)$ & $82(15)$ \\
\hline $\begin{array}{l}\text { Contextual knowledge }(\alpha=.90) ; 5 \text { items on the } \\
\text { clinician's knowledge of the patient's medical } \\
\text { history, life responsibilities, principal health con- } \\
\text { cerns, and values and beliefs }\end{array}$ & 75 (19) & $73(20)$ & $74(20)$ \\
\hline $\begin{array}{l}\text { Composite ( } \alpha=.93) \text {; average of all } 4 \text { subscales } \\
\text { weighted equally }\end{array}$ & $80(16)$ & $78^{b}(17)$ & $82(16)$ \\
\hline \multicolumn{4}{|l|}{ PCAS = Primary Care Assessment Survey } \\
\hline \multicolumn{4}{|l|}{ Note: $\alpha$ is a measure of internal reliability. } \\
\hline \multicolumn{4}{|c|}{$\begin{array}{l}\text { a Each subscale is scored from } 0 \text { to } 100 \text {, with higher scores indicating a higher level of the attribute. } \\
\text { b Score is less than that for white patients, } P<.01 \text {. }\end{array}$} \\
\hline
\end{tabular}

them. This negative association was seen to varying degrees on all 4 subscales (Figure 1) and on the composite scale $(t=2.05, P=.04)$; Table 3 shows model estimates and Figure 2 shows predicted composite scale values for individual clinicians. As a concrete example, black patients rated clinicians who scored 1.0 on the IAT (strong bias) approximately 6 points lower on interpersonal treatment than clinicians who scored 0 on the IAT (no bias).

In contrast, there was no association between Latino patients' ratings and their clinicians' implicit ethnic/racial bias on any of the 4 subscales or the composite scale $(t=0.03, P=.98)$. Tests of nonlinearity with knots at IAT

Figure 1. Predicted ratings of clinicians as a function of their implicit bias (IAT) score and their patients' ethnicity/race. White patients always served as the reference group (data not shown).

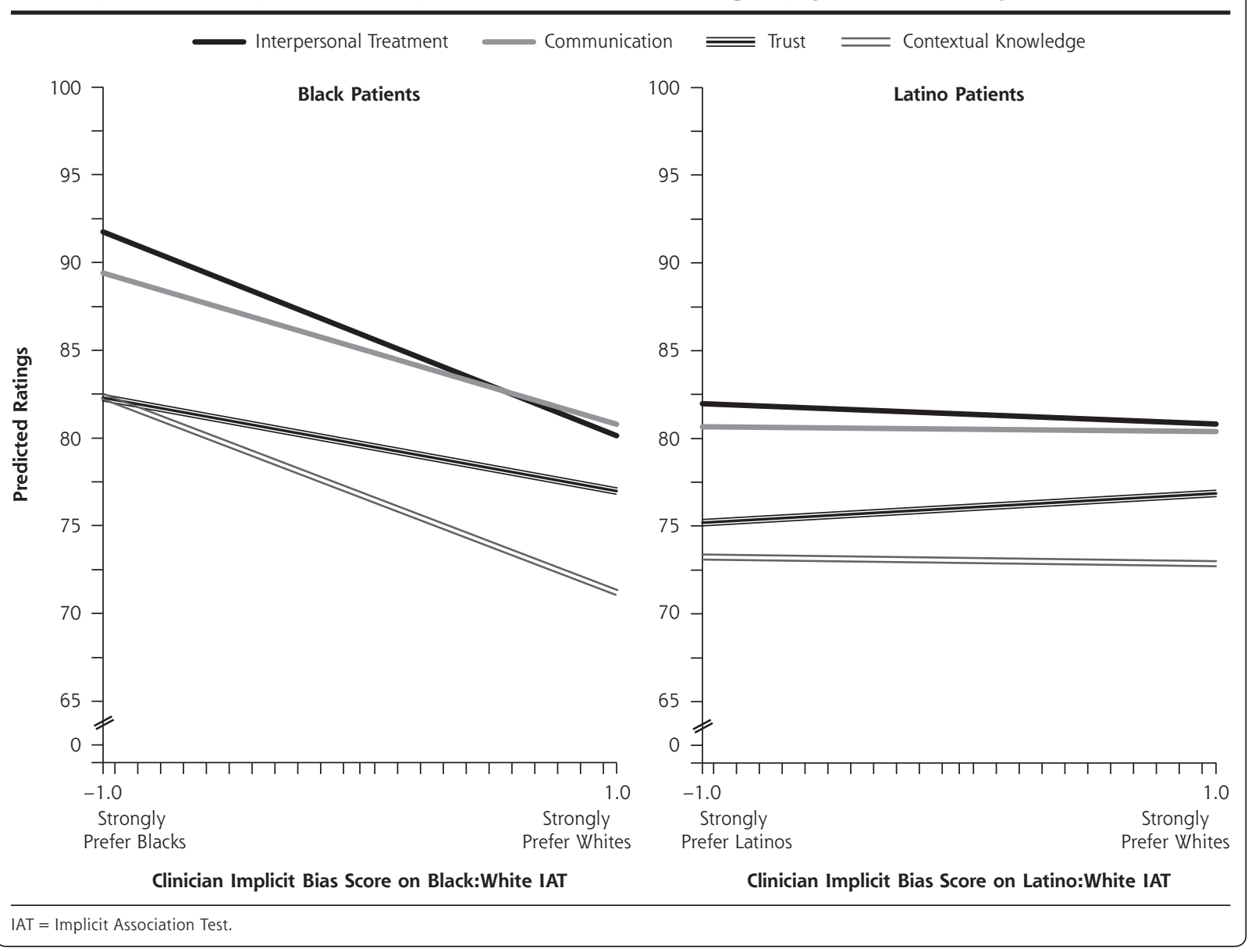


Table 3. Effects of Ethnic/Racial Group and Interactions Between Group and Clinicians' Implicit Bias on Patients' PCAS Ratings of the Clinicians

\begin{tabular}{|c|c|c|c|c|c|}
\hline \multirow[b]{2}{*}{ Predictor } & \multicolumn{5}{|c|}{ PCAS Score by Scale, Estimate (SE) } \\
\hline & $\begin{array}{c}\text { Interpersonal } \\
\text { Treatment }\end{array}$ & Communication & Trust & $\begin{array}{l}\text { Contextual } \\
\text { Knowledge }\end{array}$ & Composite \\
\hline Intercept (average rating by white patients) & $85.69(0.57)$ & $84.45(0.56)$ & $81.88(0.47)$ & $74.36(0.62)$ & $81.62(0.52)$ \\
\hline \multicolumn{6}{|l|}{ Black patients } \\
\hline Group (black vs white) & $0.24(1.11)$ & $0.64(1.10)$ & $-2.25(0.93)^{\mathrm{a}}$ & $2.42(1.22)^{\mathrm{a}}$ & $0.20(1.00)$ \\
\hline Group $\times$ clinicians' implicit bias & $-5.81(2.52)^{\mathrm{a}}$ & $-4.31(2.47)^{b}$ & $-2.65(2.09)$ & $-5.58(2.73)^{\mathrm{a}}$ & $-4.61(2.25)^{\mathrm{a}}$ \\
\hline \multicolumn{6}{|l|}{ Latino patients } \\
\hline Group (Latino vs white) & $-4.30(0.97)^{c}$ & $-3.93(0.96)^{c}$ & $-5.85(0.81)^{c}$ & $-1.31(1.06)$ & $-3.86(0.87)$ \\
\hline Group $\times$ clinicians' implicit bias & $-0.58(1.71)$ & $-0.13(1.68)$ & $0.85(1.42)$ & $-0.19(1.86)$ & $-0.04(1.53)$ \\
\hline \multicolumn{6}{|c|}{ PCAS = Primary Care Assessment Survey; $\mathrm{SE}=$ standard error. } \\
\hline $\begin{array}{l}\text { а } P<.05 . \\
\text { в } P<.09 . \\
\text { c } P<.0001 .\end{array}$ & & & & & \\
\hline
\end{tabular}

Figure 2. Predicted composite scale ratings by black, Latino, and white (reference) patients for individual clinicians with specific IAT scores.

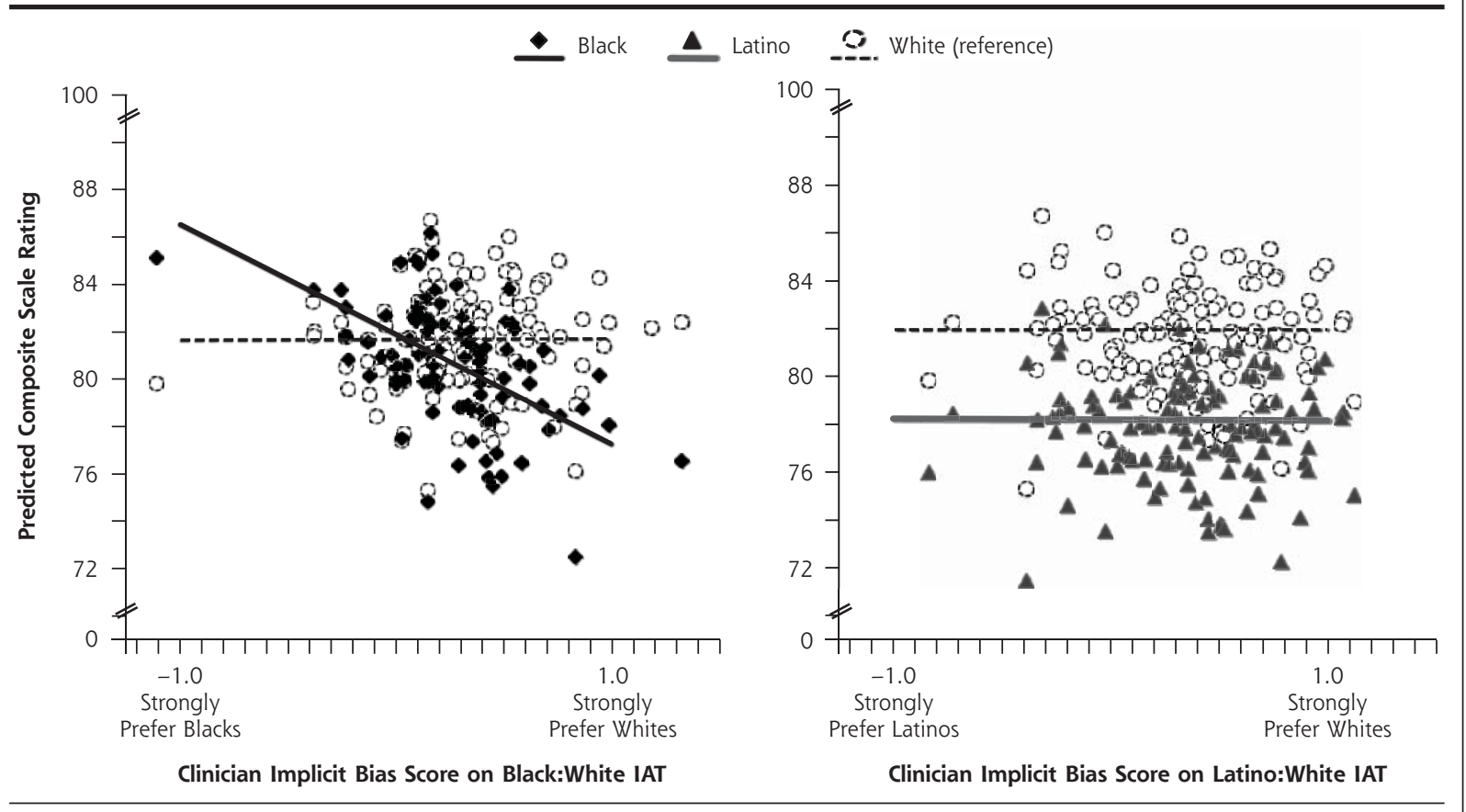

IAT = Implicit Association Test.

Note: The lines show the overall (unconditional) estimate of the relation between clinician implicit bias scores and predicted patient ratings. The symbols show the individual (conditional) estimates for each clinician with a specific IAT score by each ethnic/racial patient group.

scores of $-0.65,-0.35,0,0.35$, and 0.65 , showed that all associations (or lack thereof) were similar in magnitude across the range of bias scores (data not shown).

Patients' Ratings as a Function of Clinicians'

Explicit Bias

Neither the thermometer nor the trait rating measures of clinicians' explicit ethnic/racial bias was associated with patients' ratings of patient-centered care, for black patients (composite scale $P=.13$ and .23 ) or for Latino patients (composite scale $P=.23$ and .16).

Subgroup Analyses

For black patients, only age moderated the association between patients' ratings and clinicians' implicit bias, so that the negative association was significantly stronger 


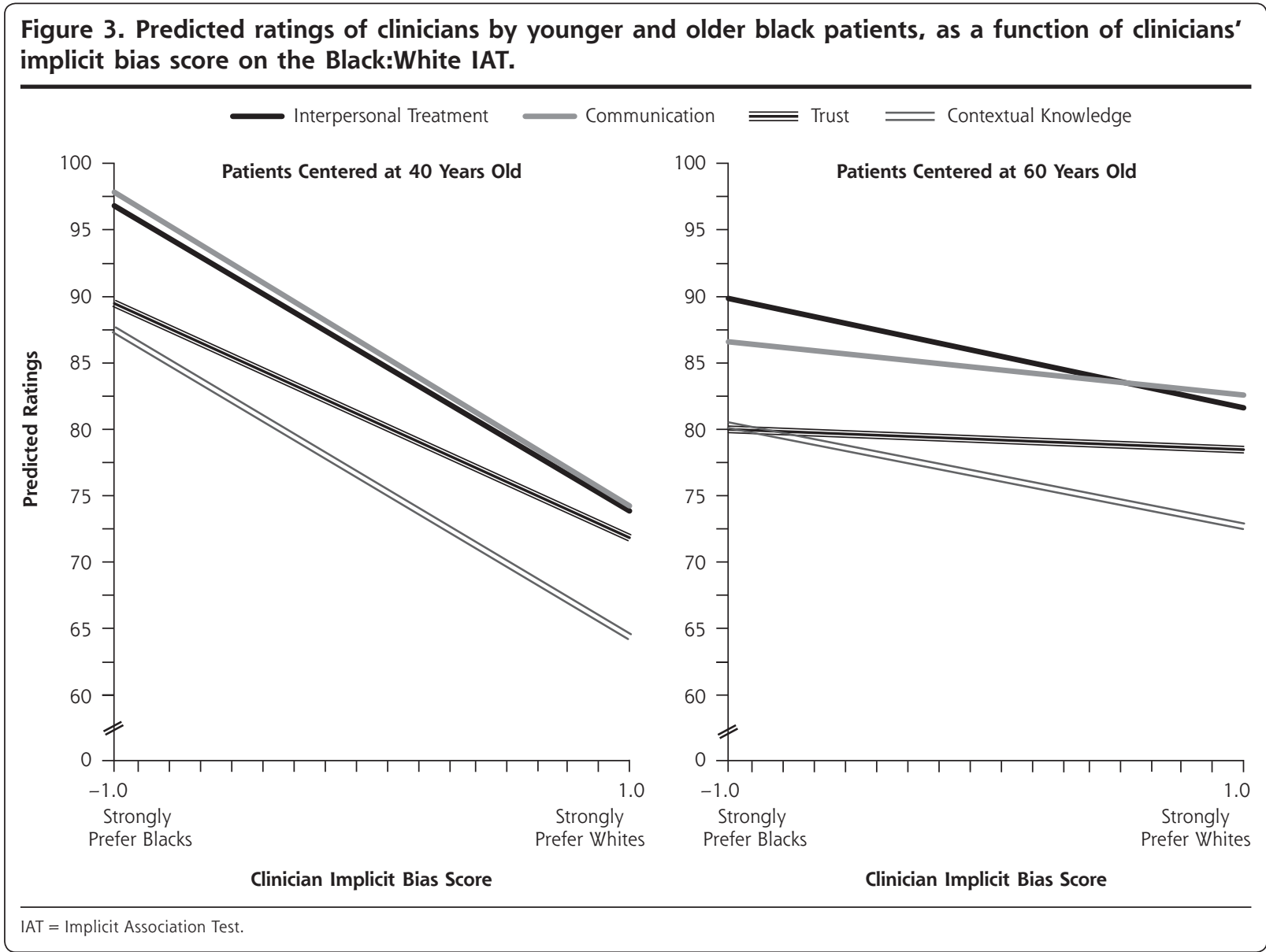

for younger than older patients; the race-by-age interaction was significant or nearly so for interpersonal treatment $(P=.06)$, communication $(P=.01)$, trust $(P=.01)$, and contextual knowledge $(P=.07)$, as well as for the composite score $(P=.02)$ (Figure 3$)$. As an example, the model showed that among blacks aged 40 years, clinicians with an IAT score of 1.0 were rated 12 points lower on communication than clinicians with a score of 0 ; among blacks aged 60 years, that difference was only 2 points. None of the background characteristics, including language, altered the primary findings for Latino patients (data not shown).

\section{DISCUSSION}

Our data show that clinicians' implicit ethnic/racial bias is related to the quality of clinical relationships for some patients: clinicians with greater implicit bias against blacks were consistently evaluated as providing less patient-centered care by their black patients than were clinicians with little or no such implicit bias. We did not assess health outcomes in this study, but prior research has shown that patients who evaluate their clinicians more positively on these same measures of patient-centeredness are more satisfied with their care, ${ }^{3}$ are more likely to adhere to treatment and follow-up with their clinician,,$^{3-5,7}$ and have better health outcomes. ${ }^{3,9}$

Although Latino patients generally gave their clinicians lower ratings than did other patient groups, these ratings were unrelated to the clinicians' ethnic/ racial bias. Even subgroups shown previously to have greater concerns with clinical interactions (eg, Spanishspeaking Latinos ${ }^{43-45}$ ) did not provide lower evaluations to more-biased clinicians. This is the first study to investigate the perceptions of Latino patients in relation to clinician bias, and the difference in findings for this group requires further investigation.

Only 2 prior studies ${ }^{46,47}$ have examined the link between clinicians' implicit bias and patients' perceptions, both with small samples of clinicians and patients. One study ${ }^{46}$ found that black patients gave lower ratings to clinicians having greater implicit race bias, but only if the clinicians also reported very low levels of explicit bias. The other study ${ }^{47}$ found more consistent associations between black patients' ratings 
and clinicians' implicit bias; however, even at higher levels of implicit race bias, black patients in that study tended to rate the clinicians more positively than did the white patients, complicating the study conclusions.

The current findings extend previous work on patient perceptions in important ways. This study was conducted with a robust sample of experienced clinicians from 2 different organizations, a large sample of patients in ongoing clinical relationships with those clinicians, validated measures of patient-centeredness (associated in prior research with patient satisfaction, adherence, and health outcomes), and a nested study design that included a large sample of white patients to more closely pinpoint ethnic/racial differences among patients who see the same clinician.

Three additional studies ${ }^{48-51}$ have examined the potential for clinicians' implicit bias to alter their clinical decision making in hypothetical scenarios. One study ${ }^{48}$ found that implicit bias was related to clinical decisions, the second ${ }^{49,51}$ produced mixed results, and the third ${ }^{50}$ did not find any association between implicit bias and clinical decisions. The small size of these studies and their reliance on hypothetical scenarios prevent a firm conclusion, but the inconsistency of results suggests that the effect of implicit bias on clinical decision making is not robust.

Our study was motivated by the hypothesis that clinicians with implicit bias may communicate differently in clinical encounters with minority patients, reducing the patients' comfort and trust in those clinicians. Our results suggest that such may be the case for black patients, but perhaps not for Latino patients. Additional investigation will be needed to determine why implicit bias is reflected in the evaluations of some groups but not others. Possible explanations include the manner in which clinicians express bias, the patients' sensitivity to it, or varying expectations and concerns.

The lack of association found in this study between clinicians' explicit bias and patients' perceptions may seem surprising - an intentionally biased clinician ought to be viewed very poorly by minority patients. As we and others have reported, however, clinicians demonstrate very little explicit bias against blacks or Latinos. ${ }^{26,48-52}$ As there is only a small probability that minority patients would encounter an explicitly biased clinician, there is little possibility of finding an association involving that form of bias.

The findings of this study are limited by several factors. As it was an observational study, a clear assignment of causality cannot be made. The lower-thandesired patient participation rate also allows for the possibility that response bias may have affected the results. The type of response bias that would explain the complex relationships obtained in this study is, admittedly, difficult to imagine. The study was restricted in scope to established primary care clinicians and their longer-term patients, specifically those with diagnosed hypertension. In our view, this restriction provides a more conservative test of the hypothesis because patients are less likely to remain with clinicians with whom they are dissatisfied.

In conclusion, patient-centeredness is a key competency in the training and professional development of health care clinicians, ${ }^{1,53}$ and its importance has been further underscored by the establishment of a national Patient-Centered Outcomes Research Institute. ${ }^{54}$ Our research shows that clinicians' implicit bias may be involved in the delivery of patient-centered care for blacks. This finding supports the contention of the Institute of Medicine ${ }^{18}$ that clinician bias may contribute to health disparities, if indirectly. What might clinicians do to avoid implicit bias in their patient interactions? Laboratory research shows that even though it is implicit, this form of bias is still malleable and changes in response to specific alterations in situational demands and social norms. ${ }^{55}$ Helping patients to respond to bias in a manner that helps to deflect a negative outcome is another path for intervention. ${ }^{55}$ For progress to be made, bias must be rendered less implicit and unconscious, to foster real reflection, analysis, and change.

To read or post commentaries in response to this article, see it online at http://www.annfammed.org/content/11/1/43.

Key words: race/ethnicity; communication; prejudice; patient-centered care; healthcare disparities; primary care; practice-based research

Submitted March 25, 2012; submitted, revised, June 20, 2012; accepted July 11, 2012.

Funding support: This study was supported by grant HL088198 from the National Heart, Lung, and Blood Institute of the National Institutes of Health.

Acknowledgments: We thank the following individuals, who were compensated for their work: Natalie Wheeler, BA (Department of Psychology and Neuroscience, University of Colorado Boulder) for assistance with the patient questionnaires; Allison Ackermann (Abt SRBI Inc) for directing and managing the collection of the patient questionnaires; Anju Gupta (Institute for Health Research, Kaiser Permanente Colorado) and Brian Eckert (Denver Health) for assistance with analyzing the electronic health record databases; and Stacie Daugherty, MD, MPH (School of Medicine, University of Colorado Denver) for her suggestions during the study and her helpful comments on this article.

\section{References}

1. Committee on the Quality of Health Care in America, Institute of Medicine. Crossing the Quality Chasm: A New Health System For the 21st Century. Washington, DC: The National Academies Press; 2001. 
2. Beach MC, Sugarman J, Johnson RL, Arbelaez JJ, Duggan PS, Cooper LA. Do patients treated with dignity report higher satisfaction adherence, and receipt of preventive care? Ann Fam Med. 2005; 3(4):331-338.

3. Safran DG, Taira DA, Rogers WH, Kosinski M, Ware JE, Tarlov AR. Linking primary care performance to outcomes of care. J Fam Pract. 1998;47(3):213-220.

4. Schneider J, Kaplan SH, Greenfield S, Li W, Wilson IB. Better physician-patient relationships are associated with higher reported adherence to antiretroviral therapy in patients with HIV infection. J Gen Intern Med. 2004;19(11):1096-1103.

5. Wilson IB, Rogers WH, Chang H, Safran DG. Cost-related skipping of medications and other treatments among Medicare beneficiaries between 1998 and 2000. Results of a national study. J Gen Intern Med. 2005;20(8):715-720.

6. Zolnierek KB, Dimatteo MR. Physician communication and patient adherence to treatment: a meta-analysis. Med Care. 2009;47(8): 826-834.

7. Safran DG, Montgomery JE, Chang H, Murphy J, Rogers WH. Switching doctors: predictors of voluntary disenrollment from a primary physician's practice. J Fam Pract. 2001;50(2):130-136.

8. Kaplan SH, Greenfield S, Ware JE Jr. Assessing the effects of physician-patient interactions on the outcomes of chronic disease. Med Care. 1989;27(3 Suppl):S110-S127.

9. Kim TW, Samet JH, Cheng DM, Winter MR, Safran DG, Saitz R. Primary care quality and addiction severity: a prospective cohort study. Health Serv Res. 2007;42(2):755-772.

10. Boulware LE, Cooper LA, Ratner LE, LaVeist TA, Powe NR. Race and trust in the health care system. Public Health Rep. 2003;118(4): 358-365.

11. Collins TC, Clark JA, Petersen LA, Kressin NR. Racial differences in how patients perceive physician communication regarding cardiac testing. Med Care. 2002;40(1 Suppl):127-134.

12. Cooper LA, Roter DL, Johnson RL, Ford DE, Steinwachs DM, Powe NR. Patient-centered communication, ratings of care, and concordance of patient and physician race. Ann Intern Med. 2003;139(11) 907-915.

13. Cooper LA, Beach MC, Johnson RL, Inui TS. Delving below the surface. Understanding how race and ethnicity influence relationships in health care. J Gen Intern Med. 2006;21(Suppl 1):S21-S27.

14. Gordon HS, Street RL Jr, Sharf BF, Kelly PA, Souchek J. Racial differences in trust and lung cancer patients' perceptions of physician communication. J Clin Oncol. 2006;24(6):904-909.

15. Johnson RL, Roter DL, Powe NR, Cooper LA. Patient race/ethnicity and quality of patient-physician communication during medical visits. Am J Public Health. 2004;94(12):2084-2090.

16. LaVeist TA, Nickerson KJ, Bowie JV. Attitudes about racism, medical mistrust, and satisfaction with care among black and white cardiac patients. Med Care Res Rev. 2000;57(Suppl 1):46-61.

17. Levinson W, Hudak PL, Feldman JJ, et al. "It's not what you say ...": racial disparities in communication between orthopedic surgeons and patients. Med Care. 2008;46(4):410-416.

18. Institute of Medicine. Smedley BD, Stith AY, Nelson AR, eds. Unequal Treatment: Confronting Racial and Ethnic Disparities in Healthcare. Washington, DC: National Academies Press; 2003.

19. van Ryn M, Fu SS. Paved with good intentions: do public health and human service clinicians contribute to racial/ethnic disparities in health? Am J Public Health. 2003;93(2):248-255.

20. Blair IV, Banaji MR. Automatic and controlled processes in stereotype priming. J Pers Soc Psychol. 1996;70(6):1142-1163.

21. Dovidio JF, Kawakami K, Gaertner SL. Implicit and explicit prejudice and interracial interaction. J Pers Soc Psychol. 2002;82(1):62-68.
22. Gawronski B, Bodenhausen GV. Associative and propositional processes in evaluation: an integrative review of implicit and explicit attitude change. Psychol Bull. 2006;132(5):692-731.

23. Fazio RH, Jackson JR, Dunton BC, Williams CJ. Variability in automatic activation as an unobtrusive measure of racial attitudes: a bona fide pipeline? J Pers Soc Psychol. 1995;69(6):1013-1027.

24. Dovidio JF, Kawakami K, Johnson C, Johnson B, Howard A. On the nature of prejudice: automatic and controlled processes. J Exp Soc Psychol. 1997;33(5):510-540.

25. McConnell AR, Leibold JM. Relations among the Implicit Association Test, discriminatory behavior, and explicit measures of racial attitudes. J Exp Soc Psychol. 2001;37(5):435-442.

26. Blair IV, Havranek EP, Price DW, et al. An assessment of biases against Latinos and blacks among primary care clinicians and community members. Am J Public Health. Published online ahead of print Nov 15, 2012: e1-e7.

27. Gabow P, Eisert S, Wright R. Denver Health: a model for the integration of a public hospital and community health centers. Ann Intern Med. 2003;138(2):143-149.

28. Nuzum R, McCarthy D, Gauthier A, Beck C. Denver Health: a high-performance public health system. The Commonwealth Fund, July 2007. http://www.commonwealthfund.org/Publications/ Fund-Reports/2007/Jul/Denver-Health--A-High-Performance-PublicHealth-Care-System.aspx. Accessed Aug 29, 2011.

29. Greenwald AG, McGhee DE, Schwartz JL. Measuring individual differences in implicit cognition: the implicit association test. J Pers Soc Psychol. 1998;74(6):1464-1480.

30. Lane KA, Banaji MR, Nosek BA, Greenwald AG. Understanding and using the Implicit Association Test: IV: What we know (so far) about the method. In: Wittenbrink B, Schwarz N, eds. Implicit Measures of Attitudes. New York, NY: Guilford Press; 2007:59-102.

31. Nosek BA, Greenwald AG, Banaji MR. Understanding and using the Implicit Association Test: II. Method variables and construct validity. Pers Soc Psychol Bull. 2005;31(2):166-180.

32. Nosek BA, Greenwald AG, Banaji MR. The Implicit Association Test at age 7: a methodological and conceptual review. In: Bargh JA, ed. Social Psychology and the Unconscious: The Automaticity of Higher Mental Processes. Florence, KY: Psychology Press; 2007:265-292.

33. Greenwald AG, Poehlman TA, Uhlmann EL, Banaji MR. Understanding and using the Implicit Association Test: III. Meta-analysis of predictive validity. J Pers Soc Psychol. 2009;97(1):17-41.

34. De Houwer J, Teige-Mocigemba S, Spruyt A, Moors A. Implicit measures: a normative analysis and review. Psychol Bull. 2009; 135(3):347-368

35. Blair IV, Judd CM, Havranek EP, Steiner JF. Using community data to test the discriminant validity of ethnic/racial group IATs. Zeitschrift für Psychologies. 2010;218:36-43.

36. The American National Election Studies. The ANES Guide to Public Opinion and Electoral Behavior. Ann Arbor, MI: University of Michigan, Center for Political Studies.

37. Smith TW, Marsden PV, Michael H, Jibum K. General Social Surveys, 1972-2010: Cumulative Codebook. National Data Program for the Social Sciences Series, no. 21. Chicago, IL: National Opinion Research Center; 2010.

38. Safran DG, Kosinski M, Tarlov AR, et al. The Primary Care Assessment Survey: tests of data quality and measurement performance. Med Care. 1998;36(5):728-739.

39. Murphy J, Chang H, Montgomery JE, Rogers WH, Safran DG. The quality of physician-patient relationships. Patients' experiences 1996-1999. J Fam Pract. 2001;50(2):123-129.

40. Montgomery JE, Irish JT, Wilson IB, et al. Primary care experiences of Medicare beneficiaries, 1998 to 2000. J Gen Intern Med. 2004;19(10):991-998. 
41. Safran DG, Wilson IB, Rogers WH, Montgomery JE, Chang H. Primary care quality in the Medicare program: comparing the performance of Medicare health maintenance organizations and traditional fee-for-service Medicare. Arch Intern Med. 2002;162(7): 757-765.

42. Taira DA, Safran DG, Seto TB, et al. Do patient assessments of primary care differ by patient ethnicity? Health Serv Res. 2001;36 (6 Pt 1):1059-1071.

43. Morales LS, Cunningham WE, Brown JA, Liu H, Hays RD. Are Latinos less satisfied with communication by health care providers? J Gen Intern Med. 1999;14(7):409-417.

44. Weech-Maldonado R, Morales LS, Elliott M, Spritzer K, Marshall G, Hays RD. Race/ethnicity, language, and patients' assessments of care in Medicaid managed care. Health Serv Res. 2003;38(3):789-808.

45. Stewart AL, Nápoles-Springer AM, Gregorich SE, Santoyo-Olsson J. Interpersonal processes of care survey: patient-reported measures for diverse groups. Health Serv Res. 2007;42(3 Pt 1):1235-1256.

46. Penner LA, Dovidio JF, West TV, et al. Aversive racism and medical interactions with black patients: a field study. J Exp Soc Psychol. 2010;46(2):436-440.

47. Cooper LA, Roter DL, Carson KA, et al. The associations of clinicians' implicit attitudes about race with medical visit communication and patient ratings of interpersonal care. Am J Public Health. 2012;102(5):979-987.
48. Green AR, Carney DR, Pallin DJ, et al. Implicit bias among physicians and its prediction of thrombolysis decisions for black and white patients. J Gen Intern Med. 2007;22(9):1231-1238.

49. Sabin JA, Rivara FP, Greenwald AG. Physician implicit attitudes and stereotypes about race and quality of medical care. Med Care 2008;46(7):678-685.

50. Haider AH, Sexton J, Sriram N, et al. Association of unconscious race and social class bias with vignette-based clinical assessments by medical students. JAMA. 2011;306(9):942-951.

51. Sabin JA, Greenwald AG. The influence of implicit bias on treatment recommendations for 4 common pediatric conditions: pain, urinary tract infection, attention deficit hyperactivity disorder, and asthma. Am J Public Health. 2012;102(5):988-995.

52. Sabin JA, Nosek BA, Greenwald AG, Rivara FP. Physicians' implicit and explicit attitudes about race by MD race, ethnicity, and gender. J Health Care Poor Underserved. 2009;20(3):896-913.

53. Greiner AC, Knebel E, eds. The Core Competencies Needed for Health Care Professionals. Health Professions Education: A Bridge to Quality. Washington, DC: National Academy Press; 2003.

54. Patient-Centered Outcomes Research Institute. 2012. http://www. pcori.org. Accessed Aug 1, 2011.

55. Blair IV, Steiner JF, Havranek EP. Unconscious (implicit) bias and health disparities: where do we go from here? Permanente J. 2011; 15(2):71-78

\section{CHANGE-OF-ADDRESS FORM FAMILY MEDICINE}

Please complete this form and mail to the following address or fax to Annals Circulation at 913-906-6080:

Annals of Family Medicine, Circulation Department, 11400 Tomahawk Creek Pkwy, Leawood, KS 66211-2680

Check if member of sponsoring organization: $\square$ AAFP $\square$ ABFM $\square$ STFM $\square$ ADFM

$\square$ AFMRD $\square$ NAPCRG $\square$ CFPC

ID number from label on your journal cover

OLD Information (Please print.)

Name

Company (if applicable)

Address (Street plus Apt or Ste)

City

Country

Postal Code (9-digit ZIP for US)

Telephone

Fax

E-Mail
NEW Information (Please print.)

\begin{tabular}{ll}
\hline Name \\
\hline Company (if applicable) \\
\hline Address (Street plus Apt or Ste) \\
\hline City & \\
\hline Country & Postal Code (9-digit ZIP for US) \\
\hline Telephone & \\
\hline E-Mail
\end{tabular}

